\title{
Non-Invasive Markers for Liver Fibrosis in Chronic HCV Patients
}

\author{
Mohamad Abd-EIrasheed ${ }^{1 *}$, Mahmoud Abd-Elrasheed $^{2}$ \\ ${ }^{1}$ Department of Tropical Medicine, ${ }^{2}$ Internal Medicine , Faculty of Medicine, Al-Azhar University, \\ Cairo, Egypt
}

* Mohamad Abd-Elrasheed,email: m-allam74@ azhar.edu.eg, mobile:01005104342

\begin{abstract}
Background: liver biopsy for years was the only trustable tool for liver cirrhosis evaluation, it is an invasive and painful procedure with considerable rate of complications. Looking for non-invasive markers was mandatory.
\end{abstract}

Aim: we aimed to evaluate the use of non-invasive markers for fibrosis staging in $\mathrm{HCV}$-infected patients.

Patient and methods: from HCV patients subjected to antiviral therapy within 2015, 42 patients were evaluated with histopathological staging (metavir-staging) after liver biopsy. According to pathological stages, our patients were divided into two groups; group (I) of 18 patients with significant liver fibrosis and group (II) of 24 patients of non-significant liver fibrosis. For all patient age, ALT, AST, GGT, cholesterol, platelets count, bilirubin, prothrombin time and albumin were evaluated and statistically correlated with fibrosis stage.

Results: patients with significant liver fibrosis had higher AST and GGT levels and lower S. Albumin and prothrombin time than patient without significant liver fibrosis. Patients with significant liver fibrosis had positive correlation between AST and GGT level and stage of fibrosis, also had negative correlation between S. Albumin, platelet count and prothrombin time and stage of fibrosis.

Conclusion: non-invasive markers as AST, GGT, serum albumin, platelet count and prothrombin time could be used as markers for diseases severity in cirrhotic patients of HCV.

Recommendation: recent studies must be done for evaluating these markers before and after HCV therapy is highly recommended.

Keywords: HCV; Hepatitis C virus, Liver biopsy and Liver Fibrosis

\section{Introduction}

Chronic HCV is the most prevalent disease in hepatology clinics. Generally, it was accepted that the diagnostic protocol of $\mathrm{HCV}$ includes a liver biopsy ${ }^{(\mathbf{1})}$. Liver biopsy is an invasive and painful procedures which has rare but potentially life- threatening complication $(2,3)$.

The prognosis and management of chronic liver disease greatly depends on the degree and progression of liver fibrosis. Liver fibrosis staging provides prognostic information ${ }^{(3,4,5)}$.

The accuracy of liver biopsy in assessing liver fibrosis has also been questioned, up to a $20 \%$ error rate in disease staging has been reported ${ }^{(4)}$.

Other testes like serum hyaluronate, procollagen III, N-peptide, laminin, type IV collagen matrix, metalloproteinase tissue inhibitory metalloproteinase -1 , transforming growth factor - beta, prothrombin index, platelets count and aspartate aminotransferase
(AST), alanine aminotransferase (ALT) ratio $>1$, from a clinical standpoint had been used for diagnosis of liver fibrosis ${ }^{(6)}$. Forns and colleagues reported a fibrosis index based on Age, Platelet count, Gamma -GT, and Cholesterol levels ${ }^{(4)}$.

Aim: We aimed to evaluate the use of noninvasive markers for fibrosis staging in $\mathrm{HCV}$ infected patients.

\section{Patients and Methods}

This study included 42 patients with chronic HCV subjected to liver biopsy between January 2014 and December 2015 before INF-based antiviral therapy. This study was performed at Al-Hussein university hospital. For all patients' written consent, full clinical assessment, laboratory and sonographic findings were recorded.

The examined patients were divided after liver biopsy into 2 groups, group (I) of 18 patients with significant liver fibrosis and 
group (II) of 24 patients of non-significant liver fibrosis.

Liver fibrosis was considered significant when it spread out of the portal tract (stages 2, 3 or 4), whereas it was considered absent when restricted to the portal tract (stage 0 or 1 respectively). ${ }^{4}$

Patients older than 65 years, alcohol addict, morbidly obese, co-infected with HBV andlor HIV were excluded.

Histological staging: Ultrasonogrphic-guided liver biopsy was performed after patient written consent. Specimens were fixed, paraffin-embedded and stained with hematoxilin and eosin, a minimum of 6 portal tracts in the specimen were required for diagnosis. All liver biopsies samples were evaluated by the same histopathologist.

\section{Statistical analysis:}

Data entry and statistical analysis were performed using the statistical package for social sciences, version 20 (SPSS Inc., Chicago, Illinois, USA). Independent-samples t-test of significance was used when comparing between two means. Pearson's correlation coefficient ( $r$ ) test was used for correlating data, $r$ value $>+0.20$ means positive correlation, $>-0.20$ means negative correlation and from -0.20 to +0.20 means no or negligible relation. $\mathrm{P}$ value $>0.05$ means nonsignificant and $<0.05$ means significant.

\section{Results}

Table (1): Baseline characteristics of studied patients

\begin{tabular}{|c|c|c|c|c|}
\hline $\begin{array}{l}\text { Characteristic } \\
\text { s }\end{array}$ & $\begin{array}{c}\text { Group-I } \\
(18)\end{array}$ & $\begin{array}{l}\text { Group- } \\
\text { II (24) }\end{array}$ & $\mathbf{t}$ & $\mathbf{P}$ \\
\hline Age (y) $M_{ \pm}$SD & $\begin{array}{c}35.11+1 \\
5.1\end{array}$ & $\begin{array}{c}33.75+1 \\
4.5\end{array}$ & $\begin{array}{c}0.29 \\
5\end{array}$ & $>0.05$ \\
\hline $\begin{array}{l}\text { AST (IU/L)> } \\
40\end{array}$ & $\begin{array}{c}69.5+18 . \\
9 \\
\end{array}$ & $\begin{array}{c}40.2+13 \\
3 \\
\end{array}$ & 2.05 & $\begin{array}{c}*<0.0 \\
5\end{array}$ \\
\hline $\begin{array}{l}\text { ALT (IU/L) > } \\
40\end{array}$ & $63.5+6.6$ & $52.9+3.2$ & $\begin{array}{c}0.74 \\
6 \\
\end{array}$ & $>0.05$ \\
\hline GGT(IU/L) & $79.9+9.4$ & $41.3+4.9$ & 2.53 & $\begin{array}{c}*<0.0 \\
5\end{array}$ \\
\hline $\begin{array}{l}\text { Bilirubin }(\mathrm{mg} / \mathrm{d} \\
\mathrm{L})>1.2\end{array}$ & $\begin{array}{c}3.43+0.3 \\
9\end{array}$ & $1.2+0.38$ & 1.69 & $>0.05$ \\
\hline $\begin{array}{l}\text { Choles. } \\
(\mathrm{mg} / \mathrm{dL})>200\end{array}$ & $218+15.0$ & $200+13.5$ & $\begin{array}{c}0.11 \\
9\end{array}$ & $>0.05$ \\
\hline $\begin{array}{l}\text { Albumin. (g/L) } \\
<3.5\end{array}$ & $2.45+0.7$ & $3.78+0.5$ & 2.09 & $\begin{array}{c}*<0.0 \\
5 \\
\end{array}$ \\
\hline $\begin{array}{l}\text { Platelets. } \\
(109 / \mathrm{L})<140 \\
\end{array}$ & $183+10.2$ & $233+13.4$ & 1.33 & $>0.05$ \\
\hline $\begin{array}{l}\text { Prothrombin } \\
\text { time }(\text { sec. })>15\end{array}$ & $16.6+4.5$ & $12.9+2.3$ & 2.12 & $\begin{array}{c}*<0.0 \\
5\end{array}$ \\
\hline
\end{tabular}

Patients with significant liver fibrosis had higher AST and GGT levels and lower S. Albumin and prothrombin time than patient with non-significant liver fibrosis (table1).

Table (2): Correlation between fibrosis and other markers in patients of group I and II

\begin{tabular}{|l|c|c|}
\hline Characteristics & $\begin{array}{c}\text { Group-I } \\
(\mathbf{n = 1 8})\end{array}$ & $\begin{array}{c}\text { Group-II } \\
(\mathbf{n = 2 4})\end{array}$ \\
\hline Age (y) M+SD & 0.0011 & -0.1101 \\
\hline AST (IU/L) & $* 0.4778$ & -0.0235 \\
\hline ALT (IU/L) & 0.0934 & -0.1767 \\
\hline GGT(IU/L) & $* 0.4012$ & -0.1308 \\
\hline Bilirubin (mg/dL) & 0.1213 & -0.1919 \\
\hline Choles. (mg/dL) & -0.0636 & -0.1663 \\
\hline Albumin. (g/L) & $* *-0.8032$ & -0.1108 \\
\hline Platelets. (109/L) & $* *-0.7332$ & -0.1966 \\
\hline Prothrombin time (sec.) & $* 0.5048$ & -0.0085 \\
\hline \multicolumn{2}{|l|}{}
\end{tabular}

*positive correlation, $* *$ negative correlation

Patients with significant liver fibrosis had positive correlation between AST, GGT and prothrombin time and stage of fibrosis, also had negative correlation S. Albumin and platelets count and stage of fibrosis. Patients with non-significant liver fibrosis had no any correlation with examined non-invasive markers. (table2)

\section{Discussion}

Liver biopsy is an invasive procedure with morbidity and carries a significant cost. ${ }^{7}$ For these reasons, several attempts have been made to use non-invasive markers for fibrosis activity evaluation. These attempts focused on advanced liver disease with bridging fibrosis or cirrhosis ${ }^{(8,9)}$.

Age, platelets count, ALT /AST ratio and prothrombin time, as well as other markers as serum albumin and cholesterol level were proportionated with $\mathrm{HCV}$ infection mainly in advanced stage of fibrosis ${ }^{(4)}$.

The aim of this study was evaluating the use of non-invasive markers for fibrosis staging in $\mathrm{HCV}$ patients.

In current study, patients with significant liver fibrosis had higher AST and GGT levels and lower S. Albumin and prothrombin time than patient with non-significant liver fibrosis.

This finding agreed with that of ImbertBismut $\boldsymbol{e t}$ al. ${ }^{(\boldsymbol{6})}$ who stated that liver function test parameters as AST, ALT, S. Albumin and prothrombin time carried not only diagnostic but also prognostic value.

The value of age as a marker of fibrosis could be explained as fibrosis progression is 
time dependent rather than related to fibrotic stage $^{(4)}$.

Significant liver fibrosis usually accompanied with progressive changes in AST\ALT GGT, Albumin, bilirubin and prothrombin time ${ }^{(4)}$.

We found that, patients with significant liver fibrosis had positive correlation between AST and GGT level and stage of fibrosis, also had negative correlation S. Albumin, platelet count and prothrombin time and stage of fibrosis. Patients with non-significant liver fibrosis had no any correlation with examined non-invasive markers.

This finding agreed with that of ImbertBismut et al. (6). Low platelet count as an indicator of sever fibrosis has been reported (10). Thrombocytopenia seems to be related to the portal hypertension and the reduced thrombopoietin ${ }^{(11)}$.

The value of ALT\AST ${ }^{(12)}$ andlor $\mathrm{GGT}^{13}$ as a marker of liver fibrosis has been described by others. Hepatitis $\mathrm{C}$ virus may cause bile duct damage and sequentially steatosis, this bile duct lesion can explain increased GGT values. ${ }^{14}$

Giannini et al. ${ }^{(13)}$ stated that, patients with bile duct lesions have significantly higher fibrosis scores and increased GGT was an independent indicator of bile duct damage.

Significant correlation between AST, GGT, serum albumin, platelet count and prothrombin time and stage of fibrosis was described in different studies ${ }^{15}$.

Conclusion: non-invasive markers as AST, GGT, serum albumin, platelet count and prothrombin time could be used as markers for diseases severity in cirrhotic patients of HCV.

Recommendation: recent studies must be done for evaluating these markers before and after HCV therapy is highly recommended.

\section{References}

1. Garcia-Bengoechea M, Emprannza JI, Sarriugarte A, Cortes A, Verga IL, Gonzales F and Arenas JI (1995): Antibodies to hepatitis $\mathrm{C}$ a cross-sectional study in patients in patients attending a trauma unit or admitted to hospital for elective surgery. Euro J Gastroenterol Hepatol., 7:237-241.

2. Perrillo RP (1997): The role of liver biopsy in hepatitis C. Hepatology, 26 (1):57S-16S.
3- International Consensus conference on hepatitis C (1999): Paris, 26-27 February 1999. Consensus statements. J Hepatology ,3(1):3-8.

4- Forns X, Ampurdanes S, Sanchez-Tapias JM, Guilera M, Sans M, SanchesFueyoA and Quinto L (2001): Long -term follow - up of chronic hepatitis $\mathrm{C}$ in patients diagnosed at a tertiary-care centre. J Hepatology, 35:265-271.

5- Yano M, Kumada H, KageM,Ikeda K, Shimamatsu $\mathrm{K}$, Inoue $\mathrm{O}$ and Hashimoto E (1996): The long-term pathological evolution of chronic hepatitis C, Hepatology, 23:1334-1340.

6- Imbert-Bismut F, Ratziu V, PieroniL, Charlotte F, Benhamou $Y$ and Poyanard T (2001): Biochemical markers of liver fibrosis in patients $\mathrm{C}$ virus infection:a prospective study. Lancet, 357:1069-1075.

7- Cadranel JF and Rufat DF (2000): Practices of liver biopsy in France:results of a prospective nationwide survey. For the Group of Epidemiology of the French Association for the study of liver (AFEF). Hepatology, 32:477-481.

8- Oberri F, Valessia E, Pilette C, Rousselet $M$ C, Bedossa P, Aube $C$ and Gallios $Y$ (1997): Noninvasive diagnosis of hepatic fibrosis or cirrhosis. Gastroentology, 113:1 609-1616.

9- Scheuer P (1991): Classification of chronic viral hepatitis:a need for reassessment. J Hepatol, 13:372-374.

10- Bonacini M, Hadi G, Govindarajan S and Lindsay KL (1997): Utility of a discriminate score for diagnosing advanced fibrosis or cirrhosis in patients with chronic hepatitis C virus infection. Am J Gastroentrol., 92:1302-1304.

11- Forns X,Ampuranes S, LIovent JM, Aponte $J$, Bruguera $M$ and SanchezTapias JM (2001): identification of chronic hepatitis Patients without hepatic fibrosis by a simple predictive model Hepatology, 36:986-992.

12- William AL and Hoofnagle JH (1988): Ratio of serum aspartate to alanine aminotransferase in chronic hepatitis relationship to cirrhosis. Gastroenterology, 734-739.

13- Giannini E, Ceppa P, Botta F, Fasoli A, Romagnoli P, Cresa $E$ and Venurino V (1999): Steatosis and bile duct damage in 
chronic hepatitis C: Distibution And Relationship In A Group Of Northern Italian patients. Liver, 19:432 -437.

14- Poynard T and Bedosa P (1997): Age and platelet count a simple index for predicting the presence of histological lesions in patients with antibodies to hepatitis $\mathrm{C}$ virus. METAVIR and CLINIVIR cooperative study groups' Viral Hepat., 4:199-208.

15- Diensstag G (2002): The role of liver biopsy in chronic hepatitis C. Hepatology, 36(5): s152-S160. 